Revista Española de Antropología Americana ISSN: 0556-6533

https://doi.org/10.5209/REAA.63698

\title{
Explorando las órbitas tecnológicas de dos rostros de mosaico de piedra verde de Tikal, Petén, Guatemala ${ }^{1}$
}

\author{
Juan Carlos Meléndez y Emiliano R. Melgar Tísoc ${ }^{3}$
}

Recibido: 4 de octubre de 2018 / Aceptado: 14 de noviembre de 2018

Resumen. Además de la innegable relevancia ideológica y política materializada en dos rostros de mosaico de piedra verde descubiertos en el recinto funerario de un antiguo gobernante maya de Tikal, que fue enterrado entre el año 350 d.C. y el 378 d.C., este estudio busca identificar los rasgos de manufactura de estas insignias. A través de métodos no destructivos, y con el apoyo de instrumentación microscópica de alta resolución, fueron analizados sectores específicos de teselas seleccionadas que conforman los dos rostros de mosaico. A partir de los resultados obtenidos, se sugiere el empleo de herramientas manufacturadas con materia prima local y foránea para elaborar las teselas. Asimismo, son notables las semejanzas de producción identificadas en las teselas durante las últimas fases de trabajo, mientras que en las etapas previas éstas parecen poseer significativas diferencias.

Palabras clave: maya; tecnología; lapidaria; mosaico; jade.

\section{[en] Exploring the Technology behind Two Greenstone Mosaic Faces from Tikal, Petén, Guatemala}

\begin{abstract}
Besides the undeniable political and ideological relevance materialized in two greenstone mosaic faces discovered in a sumptuous funerary precinct belonging to an ancient Maya ruler of Tikal, buried sometime between A.D. 350 and 378, this study seeks to identify the patterns of manufacture recorded on these insignias. Using non-destructive methods and high-definition microscopic approaches, sectors of select tesserae that form the two greenstone mosaic faces were analyzed. Based on the obtained results, we suggest that the tools used to manufacture the tesserae were made using local and foreign raw materials. Moreover, the technological patterns recorded on the tesserae seem to be similar during the final stages of manufacture, whereas during the earlier stages they seem to be meaningfully distinct.
\end{abstract}

Keywords: Maya; technology; lapidary; mosaic; jade.

Sumario. 1. Introducción. 2. Métodos. 3. El estudio de las máscaras 1 y 2. 4. Resultados. 5. Discusión. 6. Referencias.

Cómo citar: Meléndez, Juan Carlos y Emiliano R. Melgar Tísoc. 2018. «Explorando las órbitas tecnológicas de dos rostros de mosaico de piedra verde de Tikal, Petén, Guatemala». Revista Española de Antropología Americana 48: 191-210.

\footnotetext{
1 Este estudio fue realizado gracias a la Doctoral Dissertation Improvement Grant, otorgada por la National Science Foundation, y al apoyo de George Throop Funding y Washington University in St. Louis.

2 Washington University in St. Louis, Estados Unidos. jcmelendez@wustl.edu

3 Museo del Templo Mayor, Instituto Nacional de Antropología e Historia, México. anubismarino@gmail.com
} 


\section{Introducción}

Treinta y cinco años después del inicio del Proyecto Nacional Tikal, el cual desarrolló un amplio programa de excavaciones en el conjunto arquitectónico conocido como «Mundo Perdido» entre 1980 y 1982 (Laporte 1989), varios de los objetos allí descubiertos vuelven a ser protagonistas de estudio. Este trabajo presenta información contextual relacionada con dos probables rostros de mosaico asociados al Entierro PNT-19, descubierto en el templo central de la Plataforma Este del Grupo E (Estructura 5D-86). Las teselas que conforman estos dos rostros de mosaico, descritos aquí como Máscara 1 y Máscara 2, fueron incluidas en un estudio tecnológico dirigido a identificar rasgos de manufactura. Uno de los aspectos abordado en estas páginas es la aplicación de métodos no destructivos ni invasivos para el análisis de las teselas. El otro se centra en la discusión, a través de los resultados obtenidos, sobre la antigua producción artesanal de insignias mayas desde una perspectiva tecnológica, particularmente en la reutilización de bienes de prestigio.

\subsection{Grupo Tipo E de Mundo Perdido}

Durante las investigaciones arqueológicas realizadas por el Proyecto Nacional Tikal en Mundo Perdido se efectuó la exploración arqueológica del denominado Grupo E (Laporte 1989, 1993, 2005a; Laporte y Fialko 1990, 1995). Este grupo posee varios estadios constructivos desarrollados en distintos espacios temporales, siendo datados los más tempranos para la fase cerámica Eb Tardío (700-600 a.C.), tanto en la Pirámide Radial 5C-54 como en la Plataforma Este (Laporte y Fialko 1995: 46). Para el caso específico de la plataforma del Grupo E, estas remodelaciones se llevaron a cabo hasta la fase Imix (700-800 d.C.) (Laporte y Fialko 1995: 85). Durante su historial arquitectónico, el Grupo E incrementó su tamaño, cambiando además su diseño y estilo, aunque sin perder su forma y orientación original (Laporte y Fialko 1995) (Figura 1).

Con base en las investigaciones arqueológicas desarrolladas en Grupos E del área maya, y primordialmente sobre las plataformas que conforman estos complejos arquitectónicos, son pocos los que han reportado el hallazgo de enterramientos de alto estatus. La plataforma del Grupo E ubicado en el epicentro de Caracol es una de esas excepciones; en esta estructura fueron descubiertas tres tumbas de elevado estatus que datan del Clásico Temprano (Chase y Chase 2017: 56). Tikal se adhiere a esta exclusiva lista, ya que además del establecimiento de tres templos (5D-88, 5D-86 y 5D-84) construidos sobre la Plataforma Este durante la Fase Cauac (100 a.C. -250 d.C.), destaca la presencia de enterramientos a manera de ofrendas y quizás de gobernantes (Laporte y Fialko 1990: 35, 1995: 51). Una tumba abovedada de sección pentagonal, identificada como PNT-21 y datada entre 1 y 250 d.C., parece ser la primera manifestación funeraria de estatus elevado descubierta hasta la fecha en Mundo Perdido (Laporte 1989: 300; Laporte y Fialko 1995: 53). Posteriormente, durante la etapa final de la fase Manik II (300-378 d.C.), fueron incluidos en la mencionada plataforma seis enterramientos de alto estatus (Laporte y Fialko 1986): los enterramientos PNT-24, 25 y 26 se realizaron en la Estructura 5D-84-6, mientras que PNT-62 y PNT-63 lo hicieron en la Estructura 5D-88-6; asimismo, en la estructura central 5D-86-7 se localizó el Entierro PNT-19 (Laporte 1989: 302; Laporte y Fialko 1995: 58). Estas inhumaciones fueron cubiertas por grandes lajas de piedra caliza co- 




Figura 1. Ubicación de Tikal en el área maya y dibujo en planta del Grupo Tipo E de Mundo Perdido (tomado de Laporte 1989: fig. 138).

locadas sobre cistas recubiertas en su interior con estuco, sobre el cual fue aplicado pigmento rojo (Laporte 1989: 302; Laporte y Fialko 1995: 60). Laporte (2005b: 60) propone que estos individuos pertenecieron a un linaje que controló los destinos de Tikal durante la última parte de la fase Manik II.

\subsection{Los rostros de mosaico de piedra verde del Entierro PNT-19}

Entre el rico ajuar funerario contenido en el Entierro PNT-19, sobresale una máscara de piedra verde recuperada en varios fragmentos (Laporte 1989: 303; Laporte y Fialko 1986, 1990: 45). Actualmente este desensamblado rostro de mosaico de piedra verde se localiza en el Museo Nacional de Arqueología y Etnología de Guatemala (MUNAE), ya que en los años ochenta no se efectuó restauración alguna, probablemente por la complejidad de su ensamblaje y su complicada interpretación contextual. En 2015, al realizar el estudio preliminar de los mosaicos de piedra verde del Entierro PNT-19, se determinó la existencia de dos rostros de mosaico, los cuales estaban almacenados separadamente en dos cajas. Uno de estos rostros dispone de teselas de piedra verde de tonalidad clara, mientras que el segundo posee teselas de piedra verde oscuras (Figura 2). Al extenderlas sobre una superficie plana, fue evidente que éstas pudieron conformar dos rostros de mosaico. Esta diferenciación de teselas parece haber sido establecida durante algún intento de ensamblaje y restauración llevados a cabo durante la década de los ochenta. Al rostro de mosaico de tonalidad oscura lo denominaremos Máscara 1, la cual está compuesta por aproximadamente 48 teselas. Al rostro conformado por aproximadamente 45 teselas de tonalidad clara lo nombraremos Máscara 2. Con base en el código PNTJ (Proyecto Nacional Tikal Jade) escrito en una cédula incluida dentro de la caja donde se ubicaban las teselas de la Máscara 2, se confirmó que este material arqueológico efectivamente proviene de las excavaciones realizadas en Mundo Perdido. La confirmación de que 


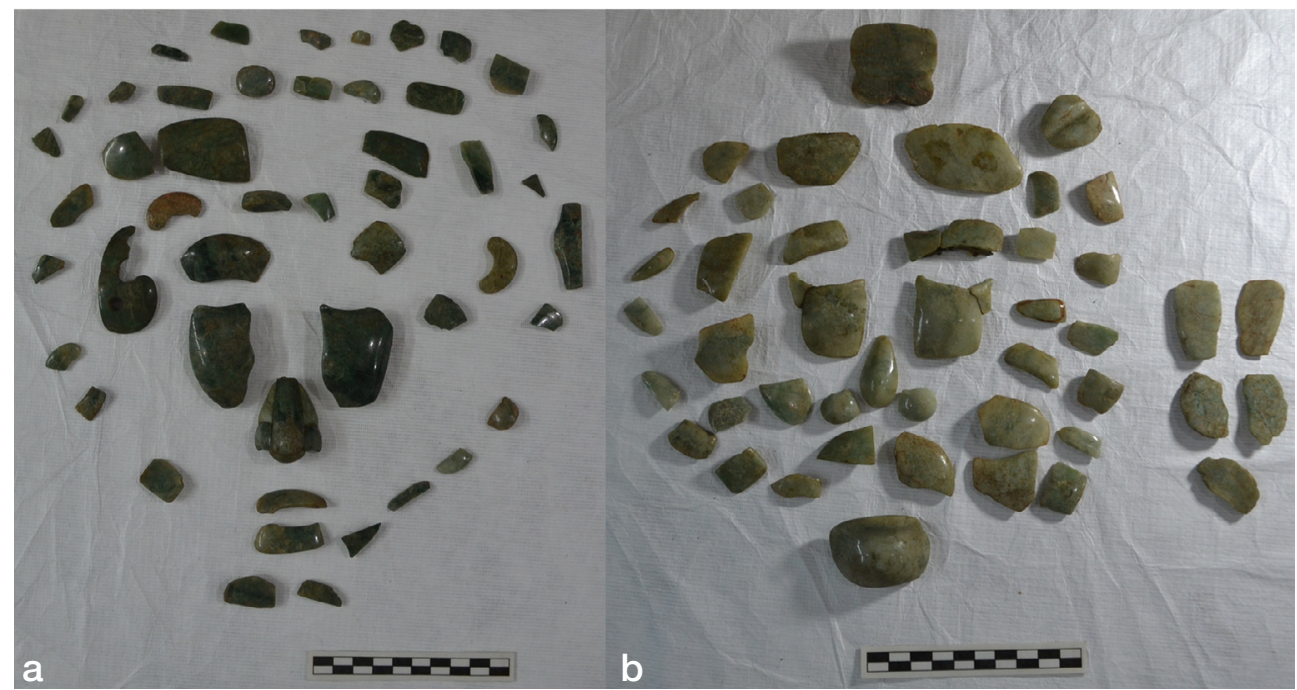

Figura 2. a) Rostro de mosaico de piedra verde conformado por teselas de tonalidad verde oscuro (Máscara 1); b) rostro de mosaico de piedra verde compuesto por teselas de tonalidad verde claro (Máscara 2).

las dos máscaras provienen del Entierro PNT-19 se obtuvo al consultar varias fotografías de las excavaciones realizadas en la estructura donde, en una de las imágenes in situ del Entierro PNT-19, se observan varias teselas de la Máscara 1 asociadas al torso del individuo. Asimismo, es posible identificar que varias teselas de tonalidad clara, seguramente de la Máscara 2, parecen estar mezcladas con las teselas oscuras de la Máscara 1 (Figura 3).

Dos imágenes tomadas en el área de restauración del MUNAE en la década de los ochenta muestran el momento en el que se intentaba ensamblar un solo rostro de mosaico con las teselas encontradas en el Entierro PNT-19. Sin embargo, lo interesante de estas imágenes es que tanto las teselas de piedra verde claras como las oscuras estaban siendo utilizadas para ensamblar un solo rostro (Figura 4). Es muy probable que, en el momento del hallazgo del Entierro PNT-19, se sugiriera que ambos tipos de teselas formaban parte de un solo rostro.

En este estudio, además de considerar la tonalidad de las teselas para sugerir la existencia de dos rostros de mosaico (Máscara 1 y Máscara 2), criterio que parece haber sido contemplado con posterioridad al intento de ensamblaje de un solo rostro, también se determinaron otros aspectos. A partir de la forma de algunas teselas, tanto de la Máscara 1 como de la Máscara 2, estas parecen formar una nariz de tonalidad clara y otra oscura, representando el dorsum nasi, las unidades alares, las unidades alares superiores y la columella. Por lo tanto, y según estimaciones llevadas a cabo durante este estudio, sería posible reconstruir dos narices, una de tonalidad verde claro y otra oscura. Durante la reconstrucción preliminar del rostro de mosaico llevada a cabo en los años ochenta, se efectuó la reconstrucción de una sola nariz empleando teselas de tonalidad clara y oscura, aspecto que posee actualmente. Asimismo, lo que podría formar el segmento de las mejillas mediales y sección baja del párpado, estaría comprendido por cuatro teselas: dos de tonalidad verde claro -lado izquierdo y derecho- y dos verde oscuro, -también de cada lado del rostro-. 


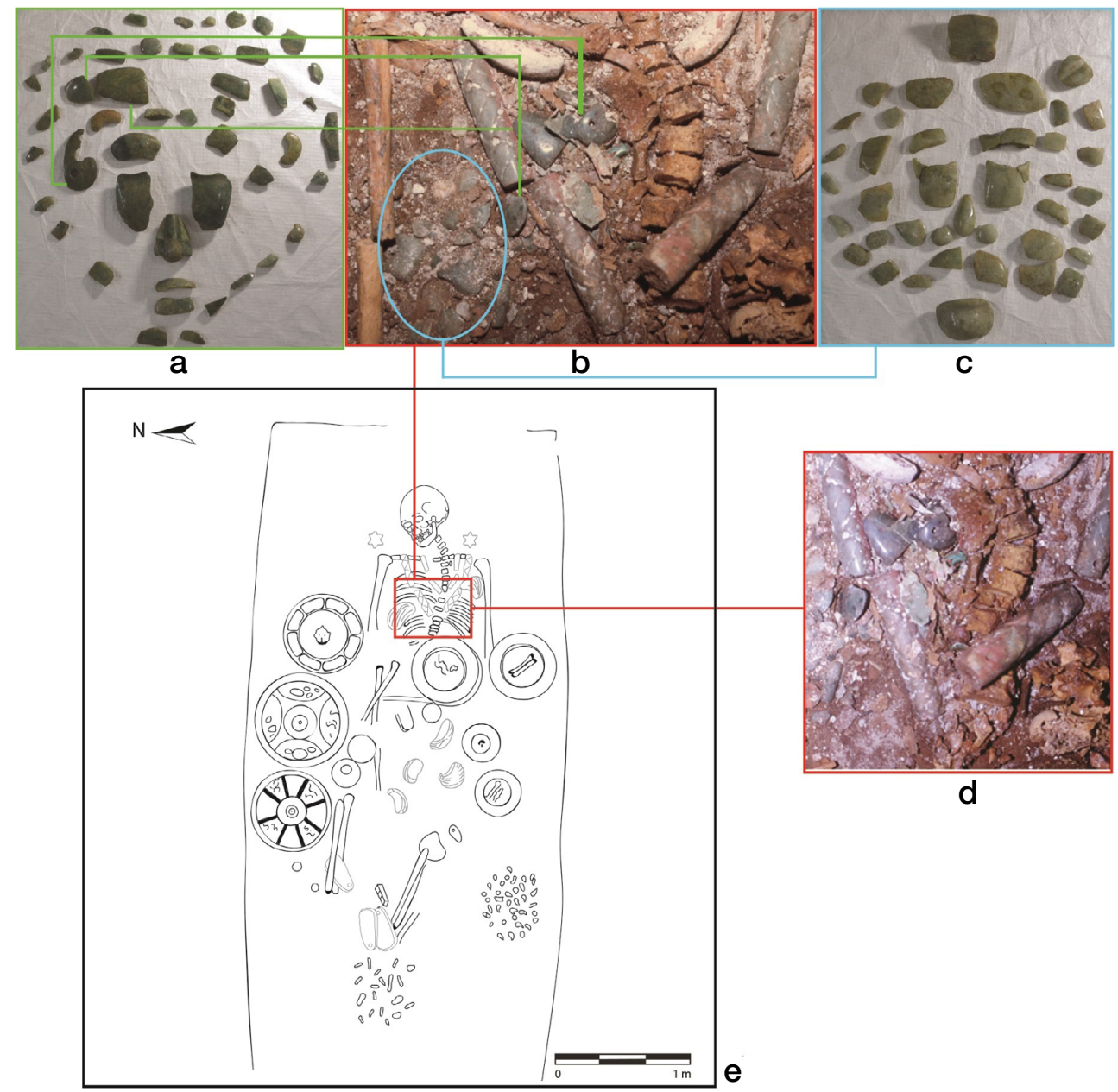

Figura 3. a) Máscara 1; b) y d) ubicación in situ de varias teselas que forman la Máscara 1 $\mathrm{y}$, probablemente, la Máscara 2, asociadas al torso del individuo que yacía en el Entierro PNT-19 (fotografía de Juan Pedro Laporte); c) Máscara 2; e) dibujo de la planta del Entierro PNT-19 (tomado de Laporte y Fialko 1995: 60).

Indudablemente, la interpretación del contexto donde se encontraron las teselas que forman el rostro o los rostros de mosaico del Entierro PNT-19 parece haber sido, cuanto menos, desafiante. $\mathrm{Y}$ aunque anteriormente se han indicado algunas razones por las que especulamos que dicho gobernante portaba no uno sino dos rostros de mosaico, se sugirió realizar un estudio tecnológico de algunas teselas selectas de las posibles Máscaras 1 y 2. A través del estudio tecnológico se procura identificar rasgos de su manufactura, los cuales podrían sugerir si las teselas de la Máscara 1 fueron elaboradas de manera similar, o si son distintas, a las de la Máscara 2. En caso de identificar diferencias tecnológicas entre las dos máscaras, podría significar que cada una fue concebida y materializada independientemente, y quizás en diferentes momentos. Por el contrario, si las teselas presentan rasgos de manufactura idénticos o similares, éstas podrían haber conformado un solo rostro, o bien las dos máscaras 



Figura 4. Propuestas de ensamblaje realizadas en la década de los ochenta, en las que se utilizaron teselas de tonalidad verde oscuro y claro para formar un solo rostro de mosaico. Cortesía del Museo Nacional de Arqueología y Etnología de Guatemala.

fueron elaboradas en un mismo momento y probablemente bajo las mismas tradiciones artesanales.

\section{Métodos}

A partir de las observaciones efectuadas en el conjunto de teselas que conforman las posibles Máscaras 1 y 2 del Entierro PNT-19 de Tikal, varias de ellas parecen haber sido extraídas de una misma fuente de piedra verde, tanto de tonalidad verde clara como oscura. Además de su tonalidad, es notable la similitud de las vetas expuestas en varias de las teselas, lo cual sugiere que las asignadas a la Máscara 1 podrían haber provenido de un mismo bloque de piedra verde, al igual que las teselas asignadas a la Máscara 2. Al iniciar el estudio tecnológico, se decidió -conjuntamente con la dirección del MUNAE - aplicar procesos de conservación preventiva al conjunto de teselas, a través de los cuales se obtuviera su ordenamiento, apreciación estética y conveniente almacenaje. Esta operación contempló mantener agrupadas las teselas según su tonalidad de verde, ya sea clara u oscura, o bien como Máscara 1 y 2.

Cada tesela fue medida y pesada y, además, con base en la tabla Munsell para rocas, les fue asignado uno o varios códigos según las tonalidades de verde más representativas contenidas en su superficie. Asimismo, cada una de las teselas fue fotografiada en su lado anterior y posterior. Para este estudio se determinó que el lado anterior de cada tesela tiene una superficie uniforme, pulida y quizás bruñida, distinta del posterior, que posee una superficie burda y no uniforme. El material empleado sobre el cual se colocaron las teselas para su almacenaje, fueron pliegos de esponja laminada de $1 \times 1 \mathrm{~m}$, libres de ácido. Sobre esta esponja se dibujó un patrón de cuadrícula, en el cual cada tesela fue colocada dentro de un rectángulo asignado con un número correlativo. La forma de cada tesela fue dibujada dentro del rectángulo asignado y, subsecuentemente y utilizando un bisturí, se cortó el perímetro dibujado, 
Figura 5. Conservación preventiva aplicada en 2015 a las teselas de piedra verde según su tonalidad:

a) Máscara 1; b) Máscara 2.

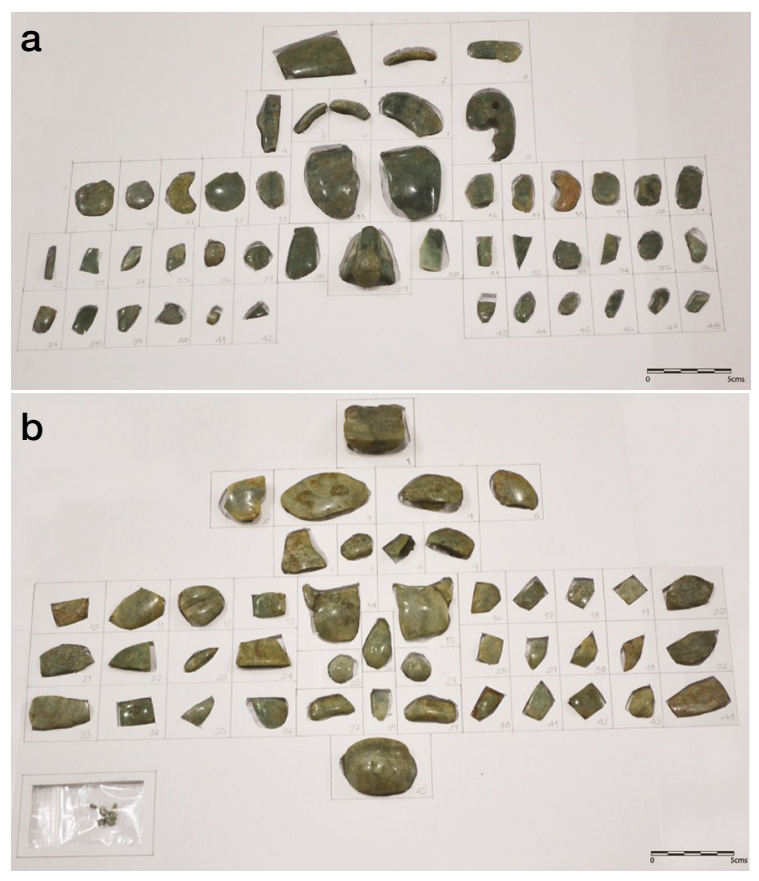

retirando parte de la esponja hasta obtener una profundidad aproximada de $0,5 \mathrm{~cm}$. De esta forma, cada tesela queda ligeramente ajustada a la esponja laminada (Figura $5 \mathrm{a}$ y b). El número asignado a cada rectángulo fue colocado en su esquina inferior, evitando así numerar con tinta cada tesela ${ }^{4}$.

El lado posterior de las teselas 4 y 7 de la Máscara 1, fueron las únicas superficies donde se evidenciaron marcas significativas de manufactura, probablemente relacionadas con la extracción de estos segmentos de piedra verde. Asimismo, la Tesela 8a es la única que posee una perforación. No obstante, la Tesela $8 \mathrm{~b}$ posee rasgos que sugieren que fue perforada en algún momento, a juzgar por la hendidura parcial de una de sus orillas. En la Máscara 2, destacan las incisiones aplicadas sobre el lado anterior de las teselas 1, 21, 32, 33 y 44, mientras que la Tesela 20 posee incisiones en su lado anterior y posterior. Además, las teselas 12 y 45 presentan una acanaladura sobre su lado anterior. De las teselas incisas sobresale la 1, la cual muestra el jeroglífico $K$ 'an representado sobre su lado anterior. Aún es perceptible observar ligeros segmentos de color rojo en las incisiones de esta tesela, probablemente como resultado de la aplicación de un pigmento rojo, quizás cinabrio. Las observaciones macroscópicas brindaron importantes aportes a este estudio, particularmente para determinar qué sector de cada tesela fue potencialmente cortado, desgastado, perforado, pulido o bruñido. Regularmente, cuando las orillas son rectas y planas, parecen únicamente haber sido cortadas y ligeramente desgastadas, mientras que las orillas

\footnotetext{
4 Fueron dibujados 48 rectángulos para colocar las teselas de la Máscara 1 (ver Figura 5a). El rectángulo 8 cuenta con dos teselas ( 8 a y 8b), mientras que el 29 posee 6 teselas (29a-29f), las cuales están pegadas seguramente desde la restauración preliminar llevada a cabo en los años ochenta. Asimismo, para colocar las teselas que conforman la denominada Máscara 2 fueron dibujados 45 rectángulos (ver Figura 5b), de los cuales el 14 y 15 contienen dos teselas cada uno (14a, 14b, 15a, 15b), debido a que se encuentran pegadas.
} 
curvas parecen haber sido desgastadas con mayor intensidad a juzgar por su textura lisa.

Se llevaron a cabo también algunas observaciones microscópicas usando un microscopio digital portátil con capacidad de magnificación de 15x a 220x. Los resultados de estas observaciones mostraron algunos rasgos de manufactura, como líneas finas paralelas sobre los sectores donde se sugirieron cortes. Asimismo, y con ligera diferencia, se observaron algunas líneas finas sobre el lado anterior (pulido) de varias teselas. Sin embargo, no se puede determinar variación alguna con relación a la manufactura de estos dos sectores sobre la base de estas observaciones microscópicas sólo por la similitud de ciertos rasgos producidos por materiales diferentes.

La búsqueda de alternativas que pudieran proporcionar datos significativos para responder a nuestro cuestionamiento tecnológico, específicamente para tratar de discernir idénticos, similares o distintos rasgos de manufactura grabadas en las teselas, tuvo como resultado una productiva cooperación. Tanto por las publicaciones académicas como por las sugerencias del gremio que realiza estudios arqueométricos en el área maya, se supo de los prometedores resultados obtenidos por el proyecto «Estilo y Tecnología de los Objetos Lapidarios del México Antiguo» del Museo del Templo Mayor de México. Este proyecto se inició hace 17 años, tomando como referencia la metodología propuesta por Adrián Velázquez, investigador del Museo del Templo Mayor, centrada en el estudio de materiales conquiológicos (Melgar 2014: 235). La esencia de este proyecto radica en la realización de más de 500 experimentos, en los que se emulan los posibles procesos de manufactura llevados a cabo por antiguos artesanos. Empleando idéntica y similar materia prima reportada en el registro arqueológico de cada región de estudio (p.e., jadeitita, serpentina, obsidiana, pedernal, arena, cuarzo, travertino, etc.), se recrean las probables herramientas y su posible uso y aplicación. Si bien es imposible reconstruir con exactitud los procesos de producción a través de ejercicios experimentales, la perspectiva adquirida respecto a la manufactura de bienes culturales es percibida con espontaneidad y claridad. Sin embargo, el aporte esencial de los experimentos es que los rasgos de manufactura, resultado de los distintos procesos de producción, registran los mismos patrones que los grabados en los artefactos arqueológicos ${ }^{5}$.

\footnotetext{
5 El proyecto «Estilo y Tecnología de los Objetos Lapidarios del México Antiguo», además de efectuar ejercicios experimentales, realiza observaciones microscópicas de selectos sectores de bienes culturales. Empleando un microscopio electrónico de barrido (MEB), y siguiendo un protocolo establecido de cuatro observaciones en 100x, 300x, 600x y 1000x de una área seleccionada del artefacto arqueológico en estudio, se toman micrografías que muestran rasgos de manufactura plasmados en alta resolución. Asimismo, se realizan observaciones microscópicas de los sectores alterados de la materia prima seleccionada para su experimentación arqueológica, procurando identificar rasgos de estas modificaciones registrados en las micrografías. Al igual que con los artefactos arqueológicos, el protocolo de observación en estos materiales de experimentación se realiza en cuatro diferentes magnificaciones 100x, 300x, 600x, 1000x. A través del estudio comparativo de la colección de referencia de micrografías, obtenidas de las áreas alteradas por la experimentación arqueológica, con aquellas tomadas de los materiales arqueológicos, se busca asociar rasgos de manufactura. A través del emparejamiento de similares rasgos de manufactura es posible identificar la materia prima de las herramientas o material empleado para la modificación de la superficie de los artefactos arqueológicos. La alta resolución de las micrografías proporcionadas por el MEB, permite identificar no sólo la forma particular de rasgos de manufactura grabados en los materiales arqueológicos, sino también un rango de medidas relacionadas con el tipo de materia prima empleada para su modificación. Por ejemplo, el proyecto «Estilo y Tecnología de los Objetos Lapidarios del México Antiguo», con base en sus experimentos, ha identificado que las alteraciones provocadas por la roca caliza en materiales de piedra verde, registra bandas irregulares de alrededor de 20 ,m (Melgar 2011). Asimismo, las alteraciones que son el resultado del corte de piedra verde con lascas de pedernal registran un patrón de líneas rectas, regulares y paralelas, las cuales poseen un ancho aproximado de 2 a $4 \mathrm{~m}$ (Melgar 2011). Mientras que los registros de cortes
} 
Indudablemente, se pensó que la aplicación de este método podía tener prometedores resultados a la hora de identificar rasgos de manufactura similares o distintos en el estudio de nuestras teselas, pero existían serios obstáculos para poder realizarlo, tales como la obtención de una póliza de seguro, los trámites de autorización o el elevado costo para trasladar las teselas seleccionadas para este estudio desde Guatemala a México. Esta problemática fue abordada años atrás por el citado proyecto que, en su afán de incrementar los estudios tecnológicos y a la vez evitar en gran medida la manipulación de piezas arqueológicas, promovió la aplicación del método de réplica. Esta efectiva solución contempla reproducir un sector seleccionado de la superficie de los objetos arqueológicos en estudio, empleando una cinta específica para ello (Melgar 2014: 240; Solís 2015: 102). Este método brinda la oportunidad de realizar estudios tecnológicos sin necesidad de trasladar materiales arqueológicos a los laboratorios que cuentan con un microscopio electrónico de barrido (MEB) (Melgar 2014: 240). El método no altera, ni mucho menos destruye, el área reproducida de los materiales arqueológicos que poseen una textura estable y una consistencia sólida. Considerando que la piedra verde y en particular la jadeitita se encuentran dentro de un rango de dureza elevado, según la escala de Mohs (7), este método es perfectamente aplicable. No obstante, para el caso de materiales frágiles como madera o huesos poco estables, se sugiere evaluar su consistencia, evitando así el posible colapso del área reproducida, ya que sobre esta se ejercerá una moderada presión durante la reproducción ${ }^{6}$.

efectuados con lascas y navajas de obsidiana sobre piedra verde, muestran patrones de líneas muy irregulares que poseen un ancho aproximado de 0,6 y 1,3 rm (Melgar 2011).

6 La marca sugerida de cinta reproductora (replicating tape) es Buehler. Esta cinta, químicamente descrita como diacetato celuloso, es inodora, de apariencia traslúcida, e insoluble al agua (Buehler 2018). Aunque el ancho de la cinta reproductora es de $2,5 \mathrm{~cm}$, se sugiere cortar pequeños segmentos de aproximadamente $5 \times 5 \mathrm{~mm}$, sobre los cuales se realizará la réplica, ya que los rasgos de manufactura observados a través del MEB suelen ser de escala reducida (p.e., $\sim 0,1-0,001 \mathrm{~mm}$ ). La réplica del sector seleccionado se inicia con la aplicación de una pequeña gota capilar de acetona pura sobre cualquiera de los lados de la cinta que se suavizará por algunos segundos, tiempo en el cual deberá colocarse sobre el área seleccionada de la superficie, ejerciéndole presión con la yema del dedo durante alrededor de 30 segundos. Pasado este tiempo el segmento de cinta deberá retirarse con cuidado y almacenarse para su posterior observación a través del MEB. Otra ventaja añadida de la aplicación de este método radica en la maximización del tiempo empleado para realizar las observaciones en el MEB, ya que, en caso de efectuarlas directamente sobre los artefactos, deberá considerarse su tamaño y sectores a analizar. Debido a que la base circular que porta las muestras y que se ajusta al compartimento de observación del MEB, suele tener un tamaño limitado de aproximadamente $15 \mathrm{~cm}$ de diámetro, este factor ha desvanecido los intentos por estudiar artefactos que sobrepasen estas dimensiones. Sin embargo, al observar a través del MEB segmentos de cinta reproducidos, los cuales son adheridos con cinta adhesiva de carbón a la base plana de pequeños cilindros de metal (de aluminio o hierro) de igual altura, permite fijar el emisor de electrones a una misma distancia. Además, el contraste visual que se obtiene al colocar un segmento de cinta reproducida sobre cinta adhesiva de tonalidad oscura como fondo, la cual se adhiere a una de las dos bases del cilindro de metal, permite vislumbrar con mejor definición los rasgos de manufactura. Seguidamente, las cintas reproducidas adheridas a los pequeños cilindros de metal son cubiertas con diminutas partículas de oro a través de un proceso de pulverización catódica realizado en un dispositivo eléctrico específico. Esta capa incrementará la conducción a través de la cinta reproducida (polímero), con lo cual se mejora la fidelidad visual de las micrografías. En la base circular que se adhiere al compartimiento de muestreo del MEB pueden incluirse aproximadamente 21 cintas reproducidas adheridas a los pequeños cilindros de metal y cubiertas con partículas de oro. Finalmente, las imágenes digitales obtenidas por el MEB pueden guardarse en varios formatos (jpg, tiff, etc.), y tamaños (p.e., $300 \mathrm{~KB}, 1,2 \mathrm{MB}$ ). 


\section{El estudio de las máscaras 1 y 2}

Al concretarse los procesos de conservación preventiva en el MUNAE, los cuales permitieron establecer un adecuado almacenaje, así como la organización y descripción básica de las teselas que conforman la Máscara 1 y 2 de Tikal, se procedió a la aplicación del método de reproducción. Solamente un seleccionado grupo de teselas que conforman las dos máscaras fueron elegidas para este estudio. A continuación se listan los pasos efectuados para la aplicación del método de réplica: 1) Inicialmente se limpió cuidadosamente el sector de la superficie de cada tesela que sería elegido para ser reproducido, utilizando un hisopo ligeramente humedecido con agua. 2) Empleando tijeras, se cortaron pequeños segmentos de cinta reproductora marca Buehler de aproximadamente $5 \times 5 \mathrm{~mm}$. 3) Con una pinza se sujetó la esquina del segmento de cinta y utilizando nuevamente las tijeras, se cortó una de las esquinas del segmento de la misma. De este modo se conocerá a qué lado de la cinta se le aplicó la gota de acetona, la cual a su vez poseerá los rasgos reproducidos del sector seleccionado de cada tesela. 4) Utilizando un gotero capilar, se aplicó una pequeña gota de acetona sobre el segmento de cinta reproductora. Este lado del segmento con acetona fue inmediatamente colocado sobre la tesela, ejerciéndole una moderada presión durante aproximadamente 30 segundos. 5) Con una pinza se levantó cuidadosamente el segmento reproducido y se almacenó dentro de una pequeña bolsa plástica de cierre hermético. Sobre esta bolsa se anotó la información contextual de la tesela, así como el número asignado durante su conservación preventiva. Asimismo, se incluyeron, al lado de los números asignados para cada tesela, letras del abecedario de forma correlativa, las cuales describen el número de réplicas realizadas en cada tesela. Además, se incluyó el tipo de rasgo de manufactura donde fue realizada la reproducción, el cual fue identificado macroscópicamente con base en su textura y apariencia (p.e., área pulida, desgastada o cortada).

Posteriormente, los segmentos de cinta reproductora (polímeros) fueron trasladados al Museo del Templo Mayor. Las observaciones microscópicas se realizaron en la Subdirección de Apoyo Académico del Instituto Nacional de Antropología e Historia, lugar donde se encuentra el MEB. La preparación de los polímeros, previa a su introducción en la cámara de observación del MEB, requirió del uso de pequeños cilindros de metal de aproximadamente $1 \mathrm{~cm}$ de alto y diámetro, a los cuales se les aplicó un pequeño segmento de cinta adhesiva de carbón de color negro, sobre una de sus dos bases. Después, los polímeros fueron colocados y pegados sobre la cinta adhesiva, con el lado reproducido orientado hacia arriba. En la base opuesta del cilindro donde fue colocado el polímero se anotó su información contextual; de esta forma el polímero está plenamente identificado durante el proceso de análisis microscópico. Antes de introducir los polímeros en la cámara de observación del MEB, éstos fueron cubiertos con diminutas partículas de oro por medio de un pulverizador catódico marca «Denton Vacuum-Desk II».

Sucesivamente, fueron colocados sobre una base circular de metal que fue ajustada al compartimiento de observación del MEB marca «Jeol JSM-6460LV». Durante la inspección microscópica, la cual es plasmada en la pantalla digital del MEB, fueron seleccionadas y grabadas las imágenes donde se identificaron rasgos de manufactura. Éstas serán comparadas con las micrografías obtenidas de las áreas modificadas por medio de procesos experimentales, las cuales ayudarán a determinar el tipo de materia prima de la herramienta utilizada para manufacturar las teselas. 


\section{Resultados}

\subsection{Máscara 1}

Las piezas seleccionadas de la Máscara 1 para este estudio fueron las teselas 14, 15 y 29.

\section{Tesela 14}

Posee un largo, ancho y grosor de 50,16 × 31,56 × 13,16 mm, pesa 31,8 g y, según los códigos de color Munsell para rocas, posee tonalidades verde grisáceo $10 \mathrm{GY}$ $5 / 2$ y verde amarillento oscuro $10 \mathrm{GY} 4 / 4$. Fueron reproducidos tres sectores de esta tesela: polímero «a» sobre el lado anterior pulido de la tesela, el cual probablemente representa la mejilla derecha del rostro; «b» y «c» sobre un posible corte que conforma el párpado inferior derecho de la máscara; «d» del lado posterior de la tesela se reprodujo un área de su sector central, la cual posee una textura rugosa.

A partir de los rasgos identificados en las micrografías de los polímeros tomados de la Tesela 14, estos muestran las siguientes características. La micrografía tomada a una magnificación de 300x del polímero «a», muestra dos bandas de 77 y $68 \mu \mathrm{m}$. Aunque éstas son ligeramente más anchas que las reportadas experimentalmente al desgastar piedra verde con roca caliza (i.e., entre 20 y $60 \mu \mathrm{m}$ ), poseen una textura similar. Mientras que la micrografía tomada a una magnificación de 1000x, muestra una textura lisa, conformada por pequeños agujeros y rayas finas de $\sim 0,60-0,95 \mu \mathrm{m}$, muy similares y casi idénticas que los rasgos identificados en las micrografías de los experimentos efectuados al frotar piedra verde con jadeitita. Estas observaciones sugieren que el lado anterior de la Tesela 14 fue desgastado con roca caliza y pulido con jadeíta. A juzgar por el limitado brillo del lado pulido de la tesela, probablemente fue ligeramente bruñida. Las micrografías del polímero «c» muestran una textura irregular de la superficie. Asimismo, fueron identificadas diminutas rayas de un ancho aproximado entre los 0,63 y $0,84 \mu \mathrm{m}$. Estos rasgos son similares a los representados en las micrografías de experimentos tomados en áreas cortadas con lascas y navajas de obsidiana, por lo que se sugiere que el área que comprendería el párpado inferior derecho del rostro, incluido en esta tesela, fue cortada con herramientas de obsidiana. Las micrografías del polímero «d» presentaron una textura rugosa, de la cual destaca una banda de textura irregular de $42 \mu \mathrm{m}$ y pequeñas rayas que poseen un ancho aproximado de $2,5 \mu \mathrm{m}$ y $3,1 \mu \mathrm{m}$. Con base en el estudio comparativo efectuado con micrografías de áreas de piedra verde modificadas experimentalmente, se determinó que la superficie posterior de la Tesela 14 podría haber sido desgastada con alguna herramienta de dacita.

\section{Tesela 15}

Posee un largo, ancho y grosor de $49,3 \times 36,14 \times 13,73 \mathrm{~mm}$, pesa 37,4 gramos $\mathrm{y}$, según los códigos de color Munsell para rocas, posee tonalidades de verde moderado $5 \mathrm{G} 5 / 6$ y verde oscuro $5 \mathrm{G} 3 / 2$. Se reprodujeron dos sectores de esta tesela: polímeros «a» sobre el lado anterior pulido de la tesela, el cual probablemente representa la mejilla izquierda del rostro; $\mathrm{y}$ «b» sobre un posible corte que conforma el párpado inferior izquierdo de la máscara. 


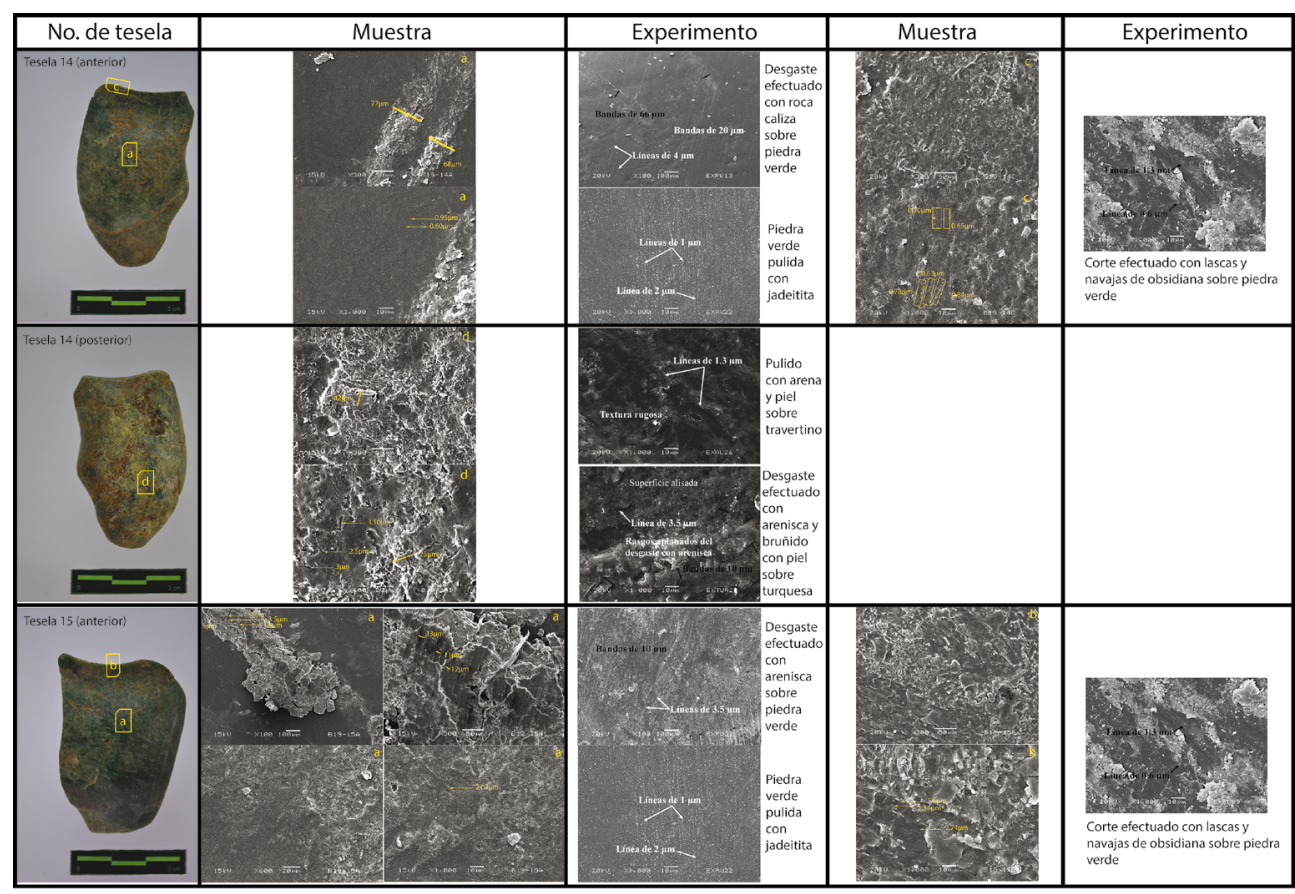

Figura 6. Estudio comparativo de las micrografías obtenidas a través del análisis tecnológico de las Teselas 14 y 15 de la Máscara 1 y ejercicios experimentales.

(Micrografías experimentales de Emiliano Melgar).

La micrografía tomada a una magnificación de 100x del polímero «a», muestra una banda irregular que posee un ancho que varía entre los $350 \mu \mathrm{m}$ y $450 \mu \mathrm{m}$ y que atraviesa una superficie de textura lisa. Sobre la banda de textura irregular se identificaron pequeñas rayas paralelas de $3,5 \mu \mathrm{m}$ y $5 \mu \mathrm{m}$, las cuales a su vez forman bandas regulares que poseen un ancho aproximado entre los $11 \mu \mathrm{m}$ y $13 \mu \mathrm{m}$, según la micrografía magnificada a 300x. El sector de superficie lisa posee un área regular, destacando únicamente una raya de 2,03 $\mu \mathrm{m}$ según la micrografía magnificada a 1000x. Las comparaciones efectuadas con micrografías que fueron el resultado de modificaciones experimentales en piedra verde, sugieren que el lado anterior de la Tesela 15 fue desgastado con una herramienta de arenisca, y posteriormente debió emplearse una herramienta de jadeitita para pulirla. Las micrografías del polímero «b» muestran una textura irregular de la superficie. Asimismo, fueron identificadas diminutas rayas de un ancho aproximado entre los 0,74 y 1,6 $\mu \mathrm{m}$. Estos rasgos son similares a los representados en las micrografías de experimentos realizados en áreas cortadas con lascas y navajas de obsidiana, por lo cual se sugiere que el área que comprendería el párpado inferior izquierdo del rostro fue cortado con herramientas de obsidiana. A juzgar por el limitado brillo del lado pulido de la tesela, probablemente no fue bruñida (Figura 6).

\section{Teselas 29-I a 29-VI}

Este fragmento de la Máscara 1, que comprende la nariz del rostro, está conformado por seis teselas, las cuales fueron identificadas como 29-I, 29-II, 29-III, 29-IV, 29-V 
y 29-VI. Debido a que estas seis teselas se encuentran adheridas con pegamento, se decidió mantenerlas unidas hasta que el MUNAE emita y apruebe una propuesta para su restauración. Esta nariz posee un largo, ancho y grosor de 38,06 $\times 31,92 \times$ $22,84 \mathrm{~mm}$, pesa $16,8 \mathrm{~g} \mathrm{y}$, según los códigos de color Munsell para rocas, presenta las siguientes tonalidades de verde: Tesela 29-I, verde amarillento oscuro, 10GY 4/4; verde amarillento fusco, $10 \mathrm{GY} 3 / 2$; verde grisáceo, $10 \mathrm{GY} 5 / 2$. Tesela 29-II, verde grisáceo, $10 \mathrm{GY} 5 / 2$. Tesela 29 -III, verde grisáceo, $10 \mathrm{GY} 5 / 2$; verde amarillento oscuro, $10 \mathrm{GY} 4 / 4$. Tesela 29-IV, verde amarillento oscuro, 10GY 4/4; verde amarillento fusco, $10 \mathrm{GY} 3 / 2$. Tesela $29-\mathrm{V}$, verde amarillo grisáceo, $5 \mathrm{GY} 7 / 2$. Tesela 29 -VI, verde amarillento pálido, $10 \mathrm{GY} 7 / 2$. Se reprodujeron tanto un sector del lado anterior de las teselas 29-I, 29-II, 29-III, 29-IV, 29-V y 29-VI, que se caracterizan por su textura lisa y uniforme, como los bordes de las teselas 29-V y 29-VI.

El polímero «a» reprodujo un área del lado pulido de las Tesela 29-I, la cual probablemente representa el dorsum nasi de la nariz. El polímero «b» reprodujo un área del lado pulido de la Tesela 29-II, la cual podría haber conformado la columella. El polímero «c» reprodujo un área del lado pulido de la Tesela 29-III, la cual pudo haber conformado la unidad alar inferior derecha. El polímero «d» reprodujo una sección del lado pulido de la Tesela 29-IV, que parece haber sido la unidad alar inferior izquierda, mientras que los polímeros «e» e «i » reprodujeron sucesivamente el área pulida y borde de la posible unidad alar superior derecha de la nariz, representada por la Tesela 29-V. Por último, los polímeros «f» y «h» reprodujeron sucesivamente el área pulida y borde de la probable unidad alar superior izquierda de la nariz, representada por la Tesela 29-VI.

La micrografía tomada a 100x del polímero «a» muestra una superficie plana sin irregularidades, mientras que la imagen magnificada a 1000x destaca un patrón de pequeños agujeros, similares a los representados en las micrografías de experimentos efectuados al pulir piedra verde con jadeitita. Entre los rasgos identificados en el polímero «b» sobresalen un reducido número de bandas de $20 \mu \mathrm{m}$ en la micrografía de 600x. Sin embargo, lo que resalta en la micrografía de 1000x es la superficie uniforme sobre la cual se identificaron pequeños agujeros. Este patrón se asemeja a los rasgos identificados en experimentos realizados al frotar piedra verde con jadeitita. Los rasgos identificados en los polímeros «c» $\mathrm{y}$ «d», son muy similares a los del polímero «b», en el cual destacan bandas de $19 \mu \mathrm{m}, 20 \mu \mathrm{m}$ y $23 \mu \mathrm{m}$ sobre una superficie lisa con pequeños agujeros. Las micrografías de los polímeros «e» $\mathrm{y}$ «f», igualmente presentan las mismas características que las anteriores, destacando las bandas irregulares de $23 \mu \mathrm{m}, 21 \mu \mathrm{m}$ y $20 \mu \mathrm{m}$ sobre una superficie lisa compuesta por pequeños agujeros. Las micrografías obtenidas de los polímeros «h» e «i» muestran una superficie muy irregular en la cual destacan pequeñas rayas de $1,06 \mu \mathrm{m}, 1,24$ $\mu \mathrm{m}, 1,7 \mu \mathrm{m}, 1,45 \mu \mathrm{m}, 1,86 \mu \mathrm{m}$ y $1,92 \mu \mathrm{m}$. Estos rasgos se asemejan a los identificados en los experimentos efectuados al cortar piedra verde con lascas y navajas de obsidiana. Los resultados de estas observaciones sugieren que el lado anterior y visualmente pulido de las teselas 29-I a 29-VI fue desgastado con alguna herramienta de roca caliza y pulido con jadeitita (Figuras 7 y 8 ).

\subsection{Máscara 2}

En la Máscara 2 se analizaron las teselas 14, 15, 26 y 45. 


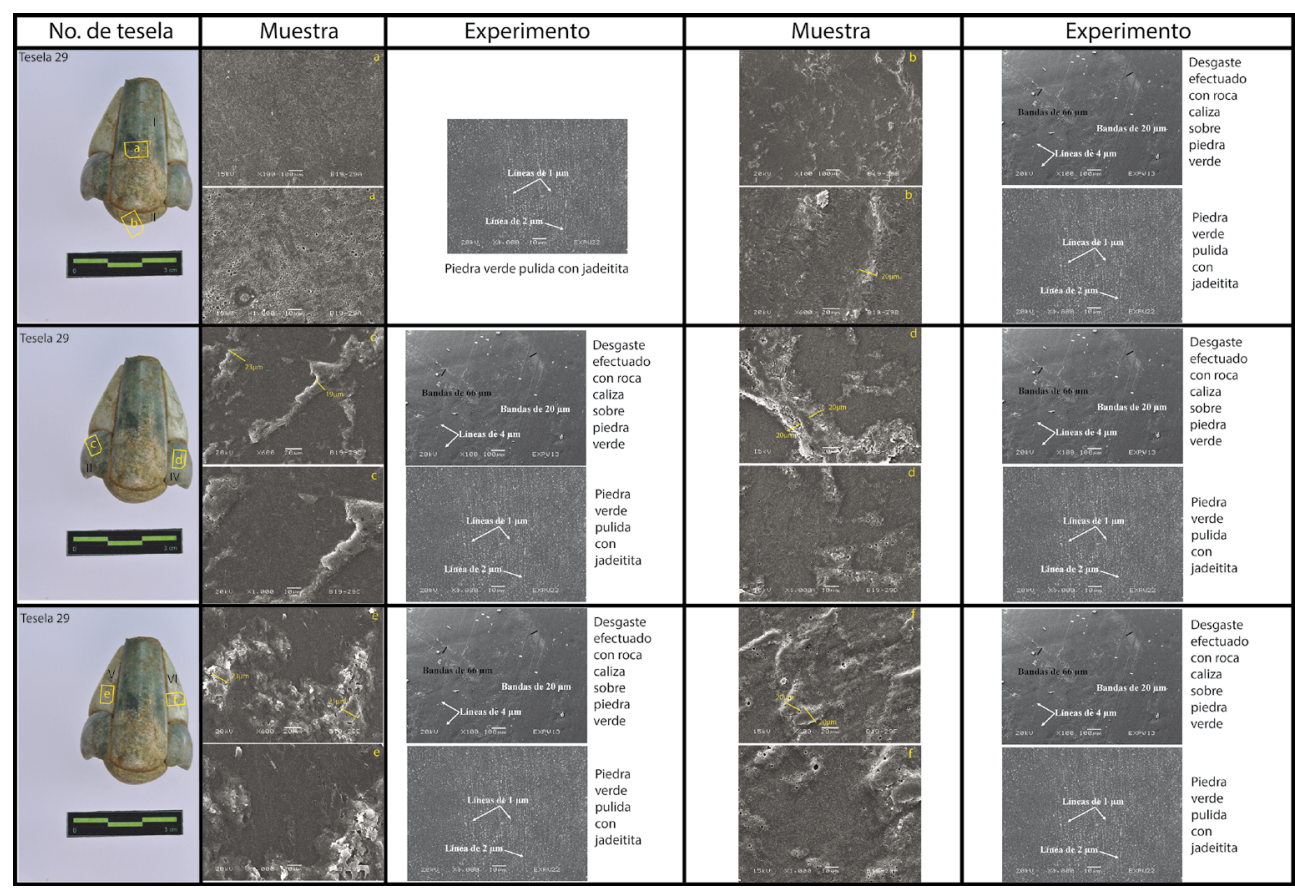

Figura 7. Estudio comparativo de las micrografías obtenidas a través del análisis tecnológico de las Teselas 29-I, II, III, IV, V y VI de la Máscara 1 y ejercicios experimentales. (Micrografías experimentales de Emiliano Melgar).

\section{Tesela 14-I}

Esta probablemente forma la mejilla medial y párpado inferior derecho del rostro. Los residuos de pegamento observados en una de las esquinas de esta tesela sugieren que en algún momento de la década de los ochenta estuvo adherida a la Tesela 14-II. La Tesela 14-I posee un largo, ancho y grosor de 33,76 × 28,95 × 6,38 $\mathrm{mm}$ y pesa 9,64 g. Según los códigos de color Munsell para rocas, posee tonalidades verde amarillo grisáceo 5GY 7/2 y verde amarillento oscuro $10 \mathrm{GY} 4 / 4$. El polímero «a» reprodujo un área del lado anterior de la tesela, el cual presenta una textura lisa, visualmente pulida. El polímero «b» se realizó en un área de su lado posterior caracterizada por poseer una superficie ligeramente irregular y rugosa. El polímero «c» reprodujo el borde del que probablemente es el párpado inferior derecho del rostro.

La micrografía de 300x obtenida del polímero «a» muestra bandas irregulares de $21 \mu \mathrm{m}, 25 \mu \mathrm{m}$ y $31 \mu \mathrm{m}$ de ancho, mientras que a 1000x presenta un área de superficie lisa con pequeños agujeros. Las micrografía de $100 \mathrm{x}$ y $1000 \mathrm{x}$ del polímero «b» presentan una textura totalmente irregular. Las observaciones efectuadas en el polímero «c» a 100x y 1000x, muestran un área irregular sobre la cual resaltan pequeñas rayas de $0,77 \mu \mathrm{m}$ y $1,07 \mu \mathrm{m}$. Contrastando los resultados experimentales con los rasgos identificados en las micrografías, se sugiere que el lado anterior de la Tesela 14-I fue desgastado con alguna herramienta de roca caliza y posteriormente pulido con algún instrumento de jadeitita. No obstante, el lado posterior de la Tesela 14-I parece haber sido desgastado con arena. Los rasgos identificados en el polímero «c» sugieren que esta área fue cortada con lascas o navajas de obsidiana (Figura 8). 


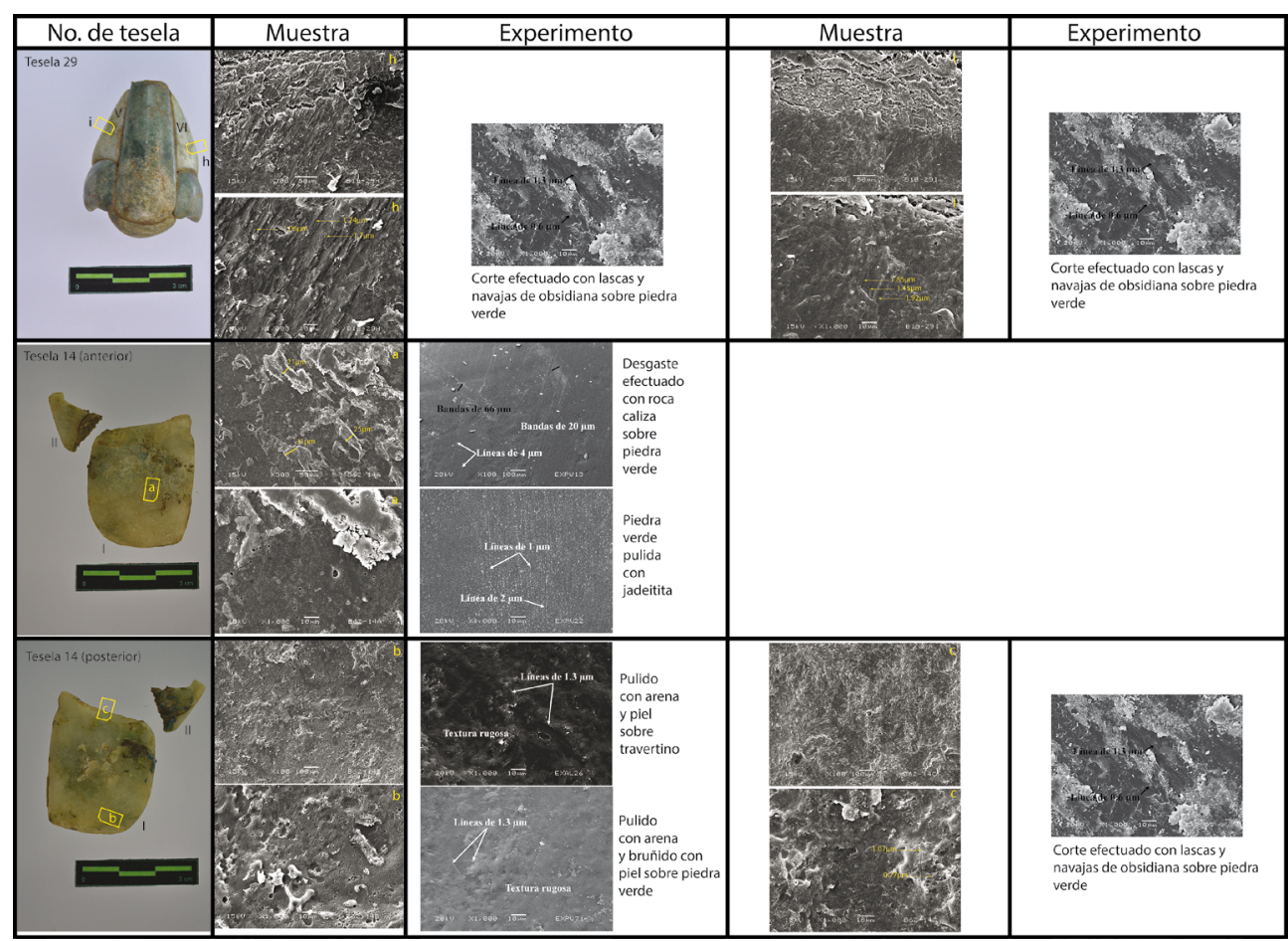

Figura 8. Micrografías tomadas durante el análisis tecnológico de les Teselas 29-V y VI de la Máscara 1 y la Tesela 14 de la Máscara 2, contrastadas con las obtenidas a través de ejercicios experimentales. (Micrografías experimentales de Emiliano Melgar).

\section{Tesela 15-I}

Este fragmento tallado en piedra verde podría conformar la mejilla medial y párpado inferior izquierdo del rostro. Esta tesela se encuentra adherida con pegamento a la Tesela 15-II. La Tesela 15-I posee un largo, ancho y grosor de 37,40 × 30,42 × 9,11 mm y, junto con la Tesela 15-II, pesa 16,93 g. Según los códigos de color Munsell para rocas, posee tonalidades verde amarillo grisáceo $5 \mathrm{GY} 7 / 2$ y verde amarillento oscuro $10 \mathrm{GY} 4 / 4$. El polímero «a» reprodujo un área del lado anterior de la tesela, que presenta una textura lisa y visualmente pulida, mientras que el polímero «b» reprodujo un área de su lado posterior caracterizado por poseer una superficie ligeramente irregular y rugosa y el polímero «c» calcó micro trazos de manufactura de una de las orillas de la tesela, la cual podría conformar el borde del párpado inferior izquierdo del rostro.

Las micrografías del polímero «a», tomadas a 300x y 1000x, muestran bandas irregulares de $30 \mu \mathrm{m}$ y $19 \mu \mathrm{m}$ sobre una superficie lisa caracterizada por la concentración de pequeños agujeros extrapolados por rayas de $0,89 \mu \mathrm{m}$ y $0,97 \mu \mathrm{m}$. Mientras que la micrografia del polímero «b» tomada a 300x presenta una superficie muy irregular, y a 1000x muestra pequeñas rayas que oscilan entre los $0,6 \mu \mathrm{m}$ y $1 \mu \mathrm{m}$. Las imágenes microscópicas extraídas del polímero «c» revelen un patrón muy irregular que se asemeja a las obtenidas a través de incisiones experimentales de lascas de obsidiana sobre piedra verde. 


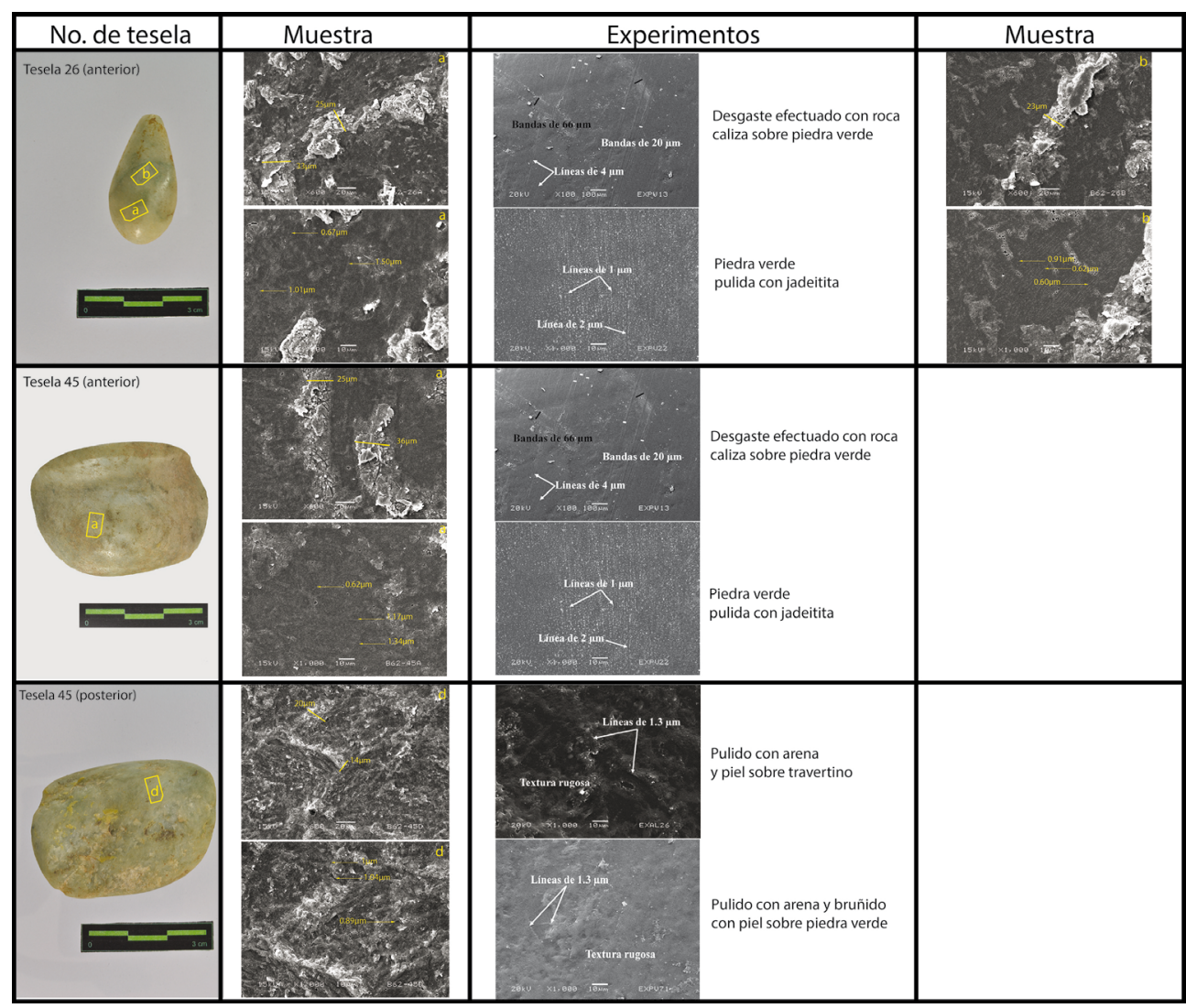

Figura 9. Estudio comparativo de las micrografías obtenidas a través del análisis tecnológico de las Teselas 26 y 45 de la Máscara 2 y ejercicios experimentales.

(Micrografías experimentales de Emiliano Melgar).

Basándonos en el estudio comparativo de micrografías con el resultado de procesos experimentales, se sugiere que el lado anterior de la Tesela 15 fue desgastado con alguna herramienta de roca caliza y, posteriormente, pulido con alguna herramienta de jadeitita. El lado posterior de la tesela parece haber sido desgastado con arena, mientras que el borde de esta tesela asociado con el párpado inferior izquierdo del rostro de mosaico, posee rasgos similares a los obtenidos en los experimentos efectuados al cortar piedra verde con lascas de obsidiana.

\section{Tesela 26}

Probablemente, este fragmento tallado en piedra verde podría ser el dorsum nasi de la nariz. Su largo, ancho y grosor es de $32,89 \times 17,1 \times 8,74 \mathrm{~mm}$ y pesa $5,22 \mathrm{~g}$. Según los códigos de color Munsell para rocas, posee tonalidades verde amarillo grisáceo 5GY 7/2 y verde amarillento oscuro $10 \mathrm{GY} 4 / 4$. Los polímeros «a» y «b» reprodujeron áreas del lado anterior que presenta una textura lisa, visualmente pulida y lustrosa. Las micrografías del polímero «a» y «b», tomadas a 600x y 1000x, muestran bandas irregulares de $23 \mu \mathrm{m}, 25 \mu \mathrm{m}$ y $33 \mu \mathrm{m}$, sobre una superficie lisa caracterizada por la concentración de pequeños agujeros extrapolados por rayas que 
poseen un ancho que oscila entre las $0,60 \mu \mathrm{m}$ y $1,50 \mu \mathrm{m}$. Contrastando los rasgos identificados en micrografías que registraron áreas modificadas experimentalmente con las obtenidas en estos polímeros, se sugiere que el lado anterior de la tesela fue desgastado empleando instrumentos de roca caliza y, posteriormente, fue pulido con alguna herramienta de jadeitita (Figura 9).

\section{Tesela 45}

Lo que podría ser el mentón del rostro de mosaico, parece estar representado en esta tesela, la cual tiene un largo, ancho y grosor de 44,18 $\times 32,88 \times 20,25 \mathrm{~mm}$, siendo su peso de $38,3 \mathrm{~g}$. Según los códigos de color Munsell para rocas, la tonalidad esta tesela se asemeja al verde amarillo grisáceo, 5GY 7/2.

El polímero «a» reprodujo un área del lado anterior de la tesela, la cual presenta una textura lisa, visualmente pulida y lustrosa. Asimismo, el polímero «d» reprodujo un área del lado posterior de la tesela, caracterizada por una textura rugosa. En las micrografías obtenidas del polímero «a», tomadas a 600x y 1000x, se identificaron bandas irregulares de $25 \mu \mathrm{m}$ y $36 \mu \mathrm{m}$, sobre una superficie lisa caracterizada por la concentración de pequeños agujeros extrapolados por rayas que poseen un ancho que oscila entre las $0,62 \mu \mathrm{m}$ y $1,34 \mu \mathrm{m}$. Las micrografías del polímero «d» muestran una superficie muy irregular, destacando la magnificada a $1000 x$, en la que se observan pequeñas rayas de $0,89 \mu \mathrm{m}, 1 \mu \mathrm{m}$ y $1,04 \mu \mathrm{m}$. Con base en las comparaciones efectuadas entre los rasgos de manufactura registrados en esta tesela y las obtenidas a través de la experimentación arqueológica, se piensa que el lado anterior de la pieza fue desgastado con algún instrumento de roca caliza. Posteriormente fue pulido empleando un instrumento de jadeitita, lo cual removió un alto porcentaje de los rasgos resultado del desgaste. Asimismo, el lado posterior de esta tesela parece haber sido desgastado con arena (Figura 9).

\section{Discusión}

Los resultados del estudio tecnológico descrito en el apartado anterior brindan una inquietante perspectiva sobre la producción artesanal prehispánica de bienes de prestigio. El contraste entre la alta definición de las observaciones efectuadas en el MEB y la comparación con los rasgos de manufactura obtenidos a través de ejercicios experimentales provee una perspectiva distinta que la resultante del estudio tecnológico de insignias ${ }^{7}$. Asimismo, la aplicación del método de réplica, el cual no es invasivo ni destructivo, genera una novedosa vía para realizar estudios tecnológicos sin exponer la integridad de los bienes culturales.

Las teselas seleccionadas para este estudio presentan rasgos de manufactura similares. Por ejemplo, los lados anteriores de las teselas fueron desgastados con algún instrumento de roca caliza; posteriormente, esta misma superficie fue frotada con algún instrumento de jadeitita hasta obtener una textura uniforme y pulida; los rasgos de manufactura identificados en sectores seleccionados de la orilla de las teselas ana-

\footnotetext{
La utilización de la palabra «insignia» guarda relación con la idea de que las máscaras estudiadas pueden considerarse no solamente como joyas decorativas de la indumentaria utilizada por individuos de elite o representaciones de ancestros, sino que pudieron tener además un propósito específico como insignias de afiliación y entronización, quizás relacionadas con el régimen imperante durante el Clásico en el reino de Kaanul.
} 
lizadas sugieren que los bordes fueron cortados con lascas o navajas de obsidiana. Pero además de estas similitudes, se identificaron también diferencias que podrían generar información relevante relativa a su manufactura. Los lados posteriores de las teselas presentan superficies muy irregulares, resultado del desgaste con arenisca en las teselas de la Máscara 1 y con arena en las teselas de la Máscara 2; asimismo, uno de los sectores analizados del lado anterior de la Tesela 15 de la Máscara 1 presentó rasgos de manufactura idénticos a los identificados en experimentos efectuados al desgastar piedra verde empleando un instrumento de arenisca.

Es notable que, de todos los bienes culturales de piedra verde con rasgos estilísticos de la cultura maya analizados a la fecha por el proyecto «Estilo y Tecnología de los Objetos Lapidarios del México Antiguo», ninguno haya presentado evidencia de haber sido manufacturado con instrumentos de arenisca. Sin embargo, objetos de piedra verde estilísticamente asociados a la cultura olmeca sí han presentado, en su mayoría, rasgos de manufactura que emulan a los realizados experimentalmente al desgastar piedra verde con arenisca. Es probable, por tanto, que varias de las teselas de la Máscara 1 de Tikal hayan sido o conformado previamente insignias olmecas, las cuales fueron modificadas para crear el rostro de mosaico maya. Probablemente, el caso más representativo relacionado con la reutilización de insignias olmecas en las que se incluyeron motivos mayas lo constituye el famoso pectoral de piedra verde de Dumbarton Oaks (Coe 1966). Esta insignia presenta una fina talla en su lado anterior que muestra un rostro felino de boca convexa, característico de la cultura olmeca, mientras que en su lado posterior se plasma la escena incisa de un gobernante maya sentado y ataviado con una extravagante indumentaria, acompañado de un texto jeroglífico. Aunque el pectoral carece de contexto arqueológico, nadie duda de su autenticidad. Este ejemplar de estilo olmeca se interpreta como muestra de la reutilización de insignias por parte de probables gobernantes mayas, a través de la cual legitimaban su vínculo divino y poder.

Por otra parte, los lados posteriores de las teselas 15 y 45 de la Máscara 2 presentaron rasgos de manufactura similares a los identificados experimentalmente al desgastar piedra verde usando dacita. Basándonos en los análisis previamente efectuados por el proyecto, los artefactos de piedra verde que mayormente han presentado este tipo de rasgos de manufactura provienen del sitio arqueológico Tak'alik Ab'aj, ubicado en la bocacosta pacífica de Guatemala (Melgar 2017, comunicación personal). Las similitudes estilísticas entre la Tesela 45, que forma parte del mentón de la Máscara 2 de Tikal, y cada una de las tres teselas que constituyen el mentón de tres de los cuatro rostros de mosaico descubiertos en el escondite de la Estructura 86 de Tak'alik Ab'aj (Schieber y Orrego 2011) constituyen otro dato a considerar. Estas semejanzas podrían estar estrechamente vinculadas a su génesis artesanal, lo que sugiere que la Tesela 45 quizás fue manufacturada o bien en Tak'alik Ab'aj, o bien siguiendo los estándares estilísticos y tecnológicos de los artesanos de esa zona de bocacosta. Posteriormente, en Tikal, la pieza fue retocada con herramientas de roca caliza y pulida con jadeitita. Este orden cronológico se basa en la datación establecida para el escondite de la Estructura 86 de Tak'alik Ab'aj (300 d.C.) y el Entierro PNT-019 (378 d.C.). Los resultados obtenidos por el Dr. Melgar sugieren que un alto porcentaje de los artefactos de piedra verde que muestran una tendencia estilística asociada con las Tierras Bajas Mayas (TBM) usualmente presentan rasgos de manufactura ejecutados con roca caliza para su desgaste y con jadeitita para su pulido (Melgar y Andrieu 2016; Monterrosa y Melgar 2017). Esta materia prima abunda 
en la región de las TBM. Sin embargo, otros rasgos de manufactura observados en los mismos artefactos sugieren el empleo de materia prima foránea para su elaboración. En el caso de Tikal, la obsidiana parece haber sido la materia prima predilecta para efectuar cortes e incisiones en piedra verde, desplazando así al pedernal, muy abundante en las TBM, mientras que los yacimientos de obsidiana se encuentran a una considerable lejanía. La piedra verde y particularmente la jadeitita, que fue la materia prima concebida para crear bienes de prestigio en la mayoría de culturas mesoamericanas, también fue utilizada como herramienta en las TBM, aunque sus afloramientos estén distantes de esta región. Pareciera que los procesos de desgaste de la piedra verde, usualmente asociados con la preparación del modelo que conformará una joya o insignia, formaron parte de las actividades burdas y convencionales entre las tareas artesanales; mientras que las tareas de corte y acabado pudieron ser realizadas con herramientas de materia prima provenientes de afloramientos distantes. Así pues, el uso en la manufactura de herramientas con valor económico o ideológico quizá sea reflejo de la relevancia de la insignia o bien de prestigio por manufacturar.

Aunque las Máscaras 1 y 2 de Tikal poseen semejanzas entre sí (p.e., número de teselas que conforman la nariz y mejillas), lo destacable son las diferencias de índole estilística y de color de la piedra verde. Con respecto a la materia prima de los instrumentos utilizados para manufacturar las teselas, es probable que éstas, antes de conformar los rostros de mosaico, hayan sido modificadas bajo distintos procesos de manufactura, quizás de dos tradiciones artesanales diferentes: la olmeca y la de la bocacosta pacífica. Adicionalmente, en el caso de la Máscara 1 es factible considerar que sus teselas fueran extraídas de lo que podría haber sido una reliquia, quizás una máscara de piedra verde de estilo olmeca de una sola pieza. No obstante, al momento de elaborar las dos máscaras, en las últimas fases del trabajo, las teselas fueron manufacturadas utilizando instrumentos de idéntica materia prima distintivos de la tradición artesanal de las Tierras Bajas Mayas.

\begin{abstract}
Agradecimientos: Además de a National Science Foundation, a George Throop Funding y a Washington University in St. Louis, se agradece a Héctor Mejía el aporte de valiosos datos que fecundaron la esencia de este trabajo. Se extiende un agradecimiento especial a David Freidel y al Instituto de Antropología e Historia de México (INAH), así como a la Subdirección de Laboratorios y Apoyo Académico del INAH y al proyecto «Estilo y Tecnología de los Objetos Lapidarios del México Antiguo» del Museo del Templo Mayor, particularmente al Dr. Emiliano Melgar por su generosa colaboración. Asimismo, se agradece la autorización de este estudio a la Dirección General del Patrimonio Cultural y Natural del Ministerio de Cultura y Deportes de Guatemala. El presente trabajo es resultado de la excelente gestión técnica y administrativa del Museo Nacional de Arqueología y Etnología de Guatemala. Esta modesta contribución antropológica conmemora el perpetuo legado de Juan Pedro Laporte Molina.
\end{abstract}

\title{
6. Referencias
}

Buehler. 2018. «Material Safety Data Sheet». https:/www.buehler.com/SDS/US/ Discontinued/9110195_US_Replicating_Tape.pdf.

Chase, Arlen y Diane Chase. 2017. «E Groups and the Rise of Complexity in the Southeastern Maya Lowlands», en Maya E Groups. Calendars, Astronomy, and Urbanism in the Early Lowlands, David Freidel, Arlen Chase, Anne Dowd y Jerry Murdock, eds., pp. 31-71. Gainesville: University Press of Florida. 
Coe, Michael. 1966. An Early Stone Pectoral from Southeastern Mexico. Washington, D.C.: Trustees for Harvard University, Dumbarton Oaks.

Laporte, Juan Pedro. 1989. Alternativas del Clásico Temprano en la relación Tikal-Teotihuacán: Grupo 6C-XVI, Tikal, Petén, Guatemala. Tesis doctoral. México: Universidad Nacional Autónoma de México.

. 1993. «Architecture and Social Change in Late Classic Maya Society: The Evidence from Mundo Perdido, Tikal», en Lowland Maya Civilization in the Eight Century A.D., Jeremy Sabloff y John Henderson, eds., pp. 299-320. Washington, D.C.: Dumbarton Oaks Research Library and Collection.

- 2005a. «Exploración y restauración en la Plataforma Este de Mundo Perdido, Tikal (Estructuras 5D-83 a 5D-89)», en XVIII Simposio de Investigaciones Arqueológicas en Guatemala, 2004, Juan Pedro Laporte, Bárbara Arroyo y Héctor Mejía, eds., pp. 147193. Guatemala: Museo Nacional de Arqueología y Etnología.

—. 2005b. «La tradición funeraria prehispánica en la región de Petén, Guatemala: una visión desde Tikal y otras ciudades», en Antropología de la Eternidad. La muerte en la cultura maya, Andrés Ciudad, Mario Humberto Ruz y Ma. Josefa Iglesias, eds., pp. 49-76. México: Sociedad Española de Estudios Mayas, Universidad Nacional Autónoma de México.

Laporte, Juan Pedro y Vilma Fialko. 1986. Una visión de Mundo Perdido, Tikal, durante el Preclásico de las Tierras Bajas Mayas. Proyecto Nacional Tikal. Reporte entregado al Instituto de Antropología e Historia de Guatemala. Manuscrito inédito.

- 1990 . «New Perspectives on Old Problems: Dynastic References for the Early Classic at Tikal», en Vision and Revision in Maya Studies, Flora Clancy y Peter Harrison, eds., pp. 33-66. Albuquerque: University of New Mexico Press.

- 1995. «Un reencuentro con Mundo Perdido, Tikal, Guatemala». Ancient Mesoamerica 6 (1): 41-94.

Melgar Tísoc, Emiliano R. 2011. La lapidaria del Templo Mayor: estilos y tradiciones tecnológicas. Archivo del Museo del Templo Mayor. Manuscrito inédito.

- 2014. Comercio, tributo y producción de las turquesas del Templo Mayor de Tenochtitlan. Tesis doctoral. México: Universidad Nacional Autónoma de México.

Melgar Tísoc, Emiliano R. y Chloé Andrieu. 2016. «El intercambio del jade en las Tierras Bajas Mayas desde una perspectiva tecnológica», en XXIX Simposio de Investigaciones Arqueológicas en Guatemala, 2015, Bárbara Arroyo, Luis Méndez Salinas y Gloria Ajú Álvarez, eds., pp. 1065- 1076. Guatemala: Ministerio de Cultura y Deportes, Instituto de Antropología e Historia y Asociación Tikal.

Monterrosa Desruelles, Hervé V. y Emiliano R. Melgar Tísoc. 2017. «La presencia maya en el Templo Mayor. Una aproximación de la jadeíta verde en las ofrendas del Huey Teocalli de Tenochtitlan», en Los investigadores de la cultura maya. El comercio y otros temas, María del Rosario Domínguez, Miriam Gallegos, Ricardo Armijo y Miriam León, eds., pp. 215-229. México: Universidad Autónoma de Campeche.

Schieber de Lavarreda, Christa y Miguel Orrego Corzo. 2012. «El retorno al ancestro en Tak'alik Ab'aj: Hallazgo del collar del ancestro del 'Señor de la Greca'», en XXV Simposio de Investigaciones Arqueológicas en Guatemala, 2011, Bárbara Arroyo, Lorena Paiz y Héctor Mejía, eds., pp. 1027-1037. Guatemala: Ministerio de Cultura y Deportes, Instituto de Antropología e Historia y Asociación Tikal.

Solís Ciriaco, Reyna. 2015. Esferas de producción y consumo de objetos lapidarios en las estructuras aledañas del Templo Mayor de Tenochtitlan. Tesis doctoral. México: Universidad Nacional Autónoma de México. 